\title{
Circulation patterns of regional mean daily precipitation extremes over the middle and lower reaches of the Yangtze River during the boreal summer
}

\author{
Zhaoyong Guan*, Jie Han, Minggang Li \\ Province-Ministry Established Key Laboratory for Meteorological Disasters, \\ Nanjing University of Information Science and Technology, Nanjing 210044, PR China
}

\begin{abstract}
By employing the composite analysis and using daily data from the National Center for Environmental Prediction/National Center for Atmospheric Research reanalysis and precipitation records at 743 stations in China, the anomalous circulation patterns for the regional mean daily precipitation extreme (DPE) events over the middle and lower reaches of Yangtze River (MLRYR) in June, July and August of the boreal summer during the period from 1979 to 2008 were investigated. This analysis determined that there have been 93 DPE events in the past $30 \mathrm{yr}$. Two types of anomalous circulation patterns were revealed in association with these DPE events. A Type I circulation pattern demonstrates an anomalous cyclone over MLRYR and an anomalous anticyclone in the South China Sea (SCS) and tropical northwestern Pacific Ocean (NWP) in the lower troposphere. An anomalous anticyclone in the upper troposphere exists in the region south of the MLRYR. The water vapor is transported not only from the Bay of Bengal, the SCS and the NWP, but also from areas northwest of the MLRYR. The apparent heating anomalies are favorable for intensifying the anomalous vertical meridional circulations in East Asia. The pattern of sea surface temperature anomalies (SSTAs) in the Indo-Pacific sector looks similar to the SSTA pattern during the maturing and decaying phases of El Niño episodes. Of the 93 DPE events 16 were induced by a Type II circulation pattern. This pattern looks largely different from the Type I pattern in aspects of distributions of anomalous winds, divergence, water vapor sources, thermal forcings and SSTAs. These results will help us understand the occurrences of DPE events in the MLRYR.
\end{abstract}

KEY WORDS: Daily precipitation extremes $\cdot$ Circulation patterns $\cdot$ Diabatic heating $\cdot$ Yangtze River $\cdot$ China $\cdot$ Boreal summer

\section{INTRODUCTION}

An increasing amount of attention has been given to weather and climate extremes occurring throughout the world. The occurrences of extreme events of weather and climate are believed to be influenced by climate variations on different time scales, which include intraseasonal oscillations, interannual variabilities, interdecadal changes and especially global warming. One of the aims of the Climate Variability and Predictability (CLIVAR) project is to clarify whether the frequency of climate extremes becomes higher in the context of global warming (www.clivar. org/organization/extremes/extremes.php).

Rakhecha \& Soman (1994) investigated the 1 to $3 \mathrm{~d}$ maximal precipitation events in relation to the climate over India, indicating the distinctly increasing and decreasing trends in different zones of the coun- 
try. Subsequently, many other studies have been conducted on rainfall in the USA (Kunkel et al. 1999), Canada (Stone et al. 1999), Japan (Yamamoto \& Sakurai 1999), England (winter precipitation, Osborn et al. 2000), Sweden (wet period rainfall), South Africa, Brazil and the former Soviet Union (Groisman et al. 1999) and have shown that in these different regions where total precipitation is on the increase, it is highly possible that the number of extreme rainfall events will increase. Even for the regions where mean total precipitation decreases, heavy rainfall events and their frequency of occurrence are increasing (Buffoni et al. 1999, Manton et al. 2001).

Cavazos (1999) reported that the anomalies of winter extreme precipitation in northeastern Mexico and southeastern Texas are related to the Aleutian low, the North Pacific high, the Pacific-North America (PNA) teleconnection and El Niño Southern Oscillation (ENSO), and that the extreme precipitation occurring in Mexico and Texas is highly sensitive
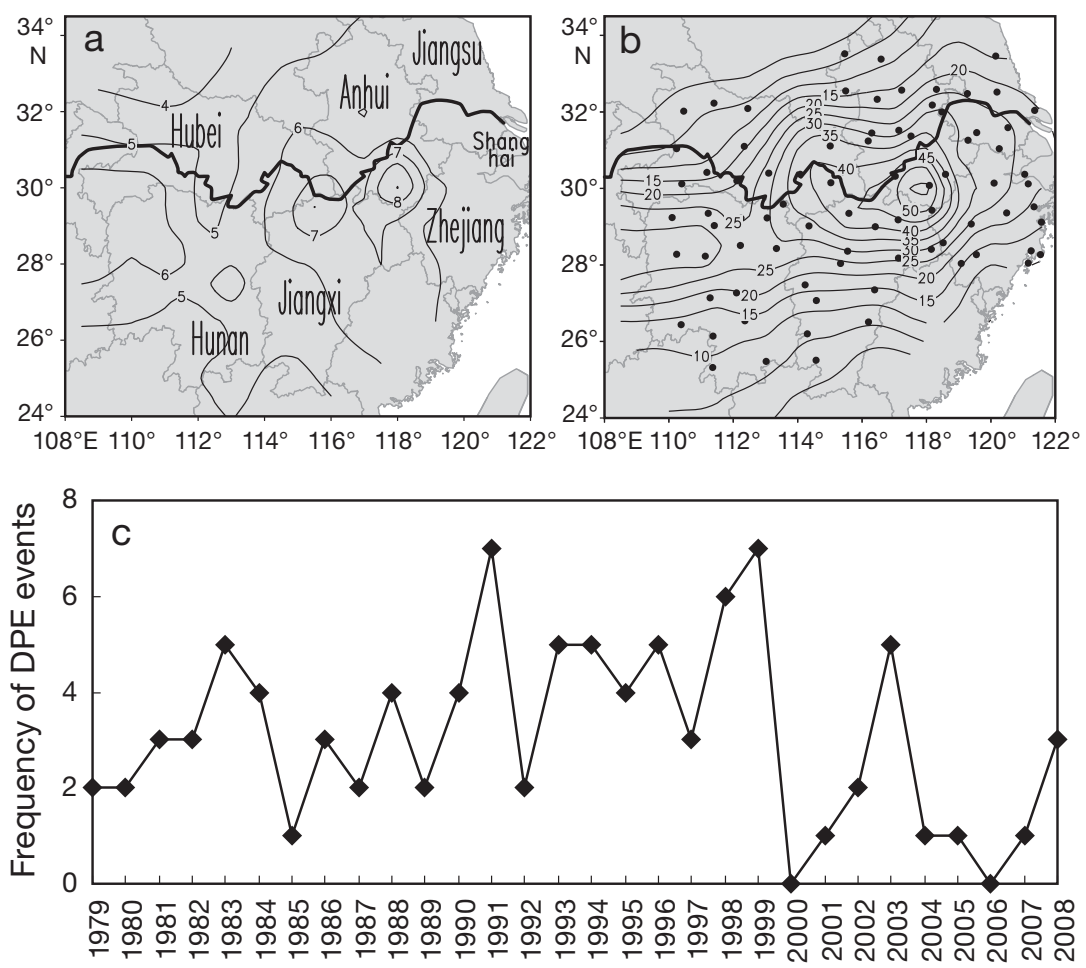

Fig. 1. (a) Summertime mean daily rainfall averaged over 30 yr from 1979 to 2008, (b) daily rainfall averaged over the 93 DPE events for each of the 84 stations and (c) annual occurrences of DPE events in MLRYR. In panels (a) and (b), the units are in $\mathrm{mmd}^{-1}$ and the thick solid lines represent the Yangtze River. Names of provinces are presented in panel (a), and the grey lines in panels (a) and (b) represent provincial borders and coastlines northern cold air outbreak. Jones (2000) examined the relationship between Californian extremes and the Madden-Julian Oscillation (MJO) by means of 1958-1996 precipitation data, outgoing longwave radiation (OLR) and the zonal wind component, and showed that most of the extreme precipitation events occur when a strong MJO occurs and when abnormal easterly or westerly winds are observed over lowlatitude areas of the Indian Ocean, indicating the extreme events are now occurring more frequently than normal.

The middle and lower reaches of the Yangtze River (MLRYR) cover the provinces of Hubei, Hunan, Jiangxi, Anhui, Jiangsu and Zhejiang and the city of Shanghai (Fig. 1a), which is one of the most important industrial and agricultural zones and densely populated regions in China. In this region, floods and droughts occur frequently. In the period from the middle of May to the middle of July in 1991, for instance, the MLRYR as well as southwestern Hubei, northwestern Hunan, and northeastern Guizhou received about 700 to $900 \mathrm{~mm}$ of rainfall with some places recording levels above $1000 \mathrm{~mm}$, which is higher than normal by 100 to $600 \mathrm{~mm}$ compared with the mean pattern of rainfall over the same period. During this event, more than 100 million people were influenced by these severe floods in Anhui, Jiangsu, Hubei, Jiangxi, Hunan and Zhejiang provinces and in Shanghai city. The direct economic loss in these regions reached more than $7 \times 10^{10}$ Chinese yuan (US $\$ 1.1 \times 10^{10}$ ) (Ding 1993). In the 1998 rainy season the MLRYR was hit by extremely severe floods. Rainfall in June through August in 1998 was measured at 700 to $900 \mathrm{~mm}$ in regions south of the Yangtze River and in southwestern Hubei, with more than $1000 \mathrm{~mm}$ of precipitation occurring in part of these regions. Eight flood crests on the Yangtze River severely affected counties along its banks and resulted in economic losses reaching as high as $2.6 \times 10^{11}$ Chinese yuan (US $\$ 4.1 \times 10^{10}$ ) (CMA National Climate Center 1999). The rain band in 2003 stayed for a long time over the Jiang-Huai valley (areas between Yangtze and Huaihe rivers) producing continual rainstorms over the Jiang-Huai and Huang-Huai regions (areas between the Huaihe and Yellow rivers) that resulted in extremely heavy floods rarely seen previously. The 
rainfall and floodwater volumes exceeded the equivalents of 1991 and many areas received precipitation in excess of the 1954 level (Bi et al. 2004, Li et al. 2008). These floods induced a large number of disasters in the MLRYR region, which stimulated scientists to investigate why and how regional precipitation extremes occur.

The statistics of precipitation events from recent $20 \mathrm{yr}$ show that the peak stage of precipitation extremes over the MLRYR takes place in June, increasing the probability of sudden floods ( $\mathrm{Su}$ et al. 2006). Qian \& Liu (2005) suggested that significantly increasing trends of extreme rainfall events occurred mainly over the MLRYR. Since 1986, flood events that have occurred more frequently in this catchment area due mainly to the intensified rainfall, and in the southeastern and southwestern parts of the MLRYR the increased frequency of such extreme precipitation events is closely related to the change in the spatiotemporal patterns of these extremes (Xie et al. 2005, Zhai \& Zou 2005, Zhai et al. 2005). Some researchers showed that the distinctly increasing trends were found in the rainfall amount, the intensity and the number of days during the precipitation extremes in the MLRYR (e.g. Liu 1999, Zhang et al. 2003, 2006).

The precipitation extremes in the MLRYR in boreal summer are usually believed to be related to the activities of weather systems including Meiyu/Baiu fronts (a quasi-stationary, zonally-oriented, baroclinic zone in the lower troposphere that typically stretches from eastern China eastward into the Pacific Ocean and south of Japan (cf. Zhang et al. 2009) along with cyclones, the western Pacific subtropical high, the east Asian summer monsoon flow (e.g. Zhao et al. 2007), typhoons and the interactions of weather systems with the topography. However, the circulation changes on interannual and even longer time scales also need to be explored. Gong et al. (2000) and Li et al. (2002) examined the regional precipitation related to the atmospheric circulation changes, and showed that not only did the variations of Arctic oscillation and anomalies of sea surface temperature (SST) in the Indo-Pacific sector affect rainfall intensities in the MLRYR in summer, but also the Indian and East Asian monsoons strongly influenced the changes in precipitation over the MLRYR.

Though some interesting results are reported in both the statistical and diagnostic studies as mentioned above, for example, why and how the daily precipitation extremes take place in the MLRYR, especially on the regional spatial scale, have not been fully understood. Therefore, in the present paper we investigate the circulation patterns that facilitate the daily precipitation extremes (DPEs) in the MLRYR on a regional spatial scale.

\section{DATA AND METHODOLOGY}

\subsection{Data}

The data used in the present study include in situ daily precipitation (rain gauge) data from 743 observation stations in China, and the National Center for Environmental Prediction/National Center for Atmospheric Research (NCEP/NCAR) reanalysis (Kalnay et al. 1996) from 1979 to 2008. The station precipitation data have been subject to quality control procedures of the Climate Data Center (CDC) (cf. Zhai et al. 2005). This data set is released by CDC of the China Meteorological Administration (CMA) and is available at http://cdc.cma.gov.cn/shuju/. The NCEP/ NCAR data have a resolution of $2.5^{\circ} \times 2.5^{\circ}$ in the horizontal scale and 17 levels in the vertical scale. In the following discussion the 'anomaly' of a physical quantity is defined as the departure of the variable from its 30 yr seasonal mean value for June, July and August combined.

The MLRYR covers a vast area to the north of the Nanling Mountains, south of Qinling Mountains and Huaihe River and east of the Wushan Mountains, i.e. 25 to $34^{\circ} \mathrm{N}$, east of $110^{\circ} \mathrm{E}$ (Fig. 1a). The 84 stations (black dots in Fig. 1b) for precipitation are selected from Hunan, Hubei, Zhejiang, Jiangxi, Jiangsu and Anhui provinces as well as the Shanghai district of this region. The remaining stations in this region were deleted because some records were missing from the time series data for rainfall at these stations during our study period. The distribution of these 84 stations is relatively homogeneous and the stations are relatively close to each other compared with the patterns for other areas of the country. To avoid errors produced in interpolation, when regional mean values were calculated, the arithmetic averaging scheme was used instead of the areal averaging method developed by Jones et al. (1986).

\subsection{Selection of DPE events}

Urban flooding may be induced when DPE events occur at a single or several stations. However, DPE events usually appear in a large area where there are many stations. These kinds of DPE events are usually dominated by large-scale dynamic processes and 
lead to severe larger-scale flooding. The MLRYR in the southern part of China is the type of place where these kinds of DPE events often occur. Therefore, the DPE events in this study are defined for the whole MLRYR rather than for a single station. For this purpose, the time series of precipitation for selecting the DPE events is obtained by averaging precipitation amounts arithmetically over the 84 stations in the region of the MLRYR.

The rainfall time series, obtained by averaging rainfall data over the 84 stations, has a time length of $2760 \mathrm{~d}$ for the summers of 1979 to 2008. After removing the events that had daily precipitation of $<1 \mathrm{~mm} \mathrm{~d}^{-1}$, the time series was rearranged by rainfall amount in an ascending order. The value at the 95th percentile was $19 \mathrm{mmd}^{-1}$, which is defined as the rainfall threshold of DPEs. In this way, all 93 DPE events were selected for their precipitation amount greater than the threshold value. The dates that these DPEs occurred are listed in Table 1. Zhai \& Pan

Table 1. Dates of the 93 daily precipitation-extreme events from 1979 to 2008 over the middle and lower reaches of the Yangtze River

\begin{tabular}{|ll|}
\hline Year & Date \\
\hline 1979 & June 4, June 25 \\
1980 & June 10, August 12 \\
1981 & June 27, June 28, July 11 \\
1982 & June 20, June 21, July 19 \\
1983 & June 2, June 20, July 1, July 4, August 23 \\
1984 & June 7, June 13, June 14, August 31 \\
1985 & June 4 \\
1986 & June 12, June 16, June 22 \\
1987 & June 1, June 7 \\
1988 & June 19, June 22, June 28, August 26 \\
1989 & June 4, August 28 \\
1990 & June 7, June 14, July 1, August 31 \\
1991 & June 8, June 13, July 1, July 3, July 6, July 9, August 23 \\
1992 & June 4, August 31 \\
1993 & June 1, June 22, June 30, July 3, July 4 \\
1994 & June 9, June 10, June 12, June 13, June 17 \\
1995 & June 3, June 21, June 25, July 1 \\
1996 & June 20, June 24, July 2, July 14, July15 \\
1997 & June 7, July 8, August 19 \\
1998 & June 18, June 24, June 25, July 22, July 23, July 29 \\
1999 & June 23, June 26, June 27, June 28, June 29, June 30, August 30 \\
2000 & none \\
2001 & June 10 \\
2002 & June 28, August 7 \\
2003 & June 24, June 25, June 27, July 5, July 10 \\
2004 & June 24 \\
2005 & August 7 \\
2006 & none \\
2007 & June 1 \\
2008 & June 9, June 10, June 17 \\
\hline
\end{tabular}

(2003) studied the extreme precipitation events in northern China and found a threshold value of $18.55 \mathrm{~mm} \mathrm{~d}^{-1}$. WMO-CCL/CLIVAR released some indices for precipitation extremes (cf. J. Wang et al. 2008), in which the days with heavy rain are defined as having daily precipitation in excess of $20 \mathrm{mmd}^{-1}$. The threshold value of $19 \mathrm{~mm} \mathrm{~d}^{-1}$ in the present work is comparable with those 2 studies and, thus, it is a reasonable regional mean value for the MLRYR.

\section{DESCRIPTION OF DAILY PRECIPITATION EXTREMES OVER THE MLRYR}

Occurrences of the 93 DPE events (Table 1) are different in different years from 1979 to 2008. The DPE events occurred more frequently in the 1990s (Fig. 1c) with the annual mean occurrences lasting more than $3.2 \mathrm{dyr}^{-1}$ longer than the $30 \mathrm{yr}$ mean, which is in agreement with Su et al. (2006). However, the DPE events occurred much less often in the 2000s than in other decades, although in 2003 there were 5 events.

The DPE events corresponded well with flood occurrences over the MLRYR. The occurrence frequency of DPE events is significantly correlated with summertime rainfall for the study period of 1979 to $2008(\mathrm{r}=0.48)$. In 1991, for example, there were 7 DPE days when the large-scale severe floods occurred over a large part of the MLRYR (Ding 1993). As shown in Table 1, the regional mean DPE occurred at a frequency of $64.5 \%$ in June, much higher than in July and August, which is apparently associated with the Meiyu/Baiu rainfall over the MLRYR from late June to early July.

Rainfall, averaged over the 93 daily precipitation extremes for the 84 stations, is plotted in Fig. 1b. In comparison with the $30 \mathrm{yr}$ mean pattern of summertime daily rainfall (Fig. 1a), the daily rainfall amounts are much higher during the DPE events (Fig. 1b). Rainfall amounts greater than $25 \mathrm{~mm} \mathrm{~d}^{-1}$ were found at all stations of the central MLRYR, and the maxima exceeded $50 \mathrm{~mm} \mathrm{~d}^{-1}$ in the area where Anhui, Jiangxi and Zhejiang provinces 
border each other (Fig. 1a). The secondary maximum value $\left(>30 \mathrm{mmd}^{-1}\right.$ ) was found in northwestern Hunan.

\section{DPE-RELATED CIRCULATION PATTERNS}

\subsection{Horizontal and vertical circulations}

The occurrences of DPEs in the MLRYR are intimately related with the East Asian summer monsoon circulation anomalies. Circulations in the lower troposphere (Fig. 2a) clearly show an anomalous cyclone over the eastern part of China along with an anomalous anticyclone over the South China Sea (SCS) and tropical part of the NWP. The anomalous cyclone over the MLRYR region is responsible for the DPEs because it is a very important, large-scale, background circulation system. Usually, for a particular DPE event, a mesoscale process such as a strong convection along a cold front in the cyclone may be very active. Existence of the strong anomalous cyclone over the MLRYR is favorable for the strong convections in the cyclone area. The anticyclone over the SCS and NWP is a key system that reinforces the cyclone north of it to occupy the MLRYR region owing to Rossby wave propagations (Nitta 1987). The divergent air flows that emanate from the Bay of Bengal, SCS, NWP and even regions east of the islands of Japan converge into the cyclone over the MLRYR.

In boreal summer, the western Pacific subtropical high (WPSH) plays a prominent role in determining the place where the Maiyu rain band will remain stationary (cf. Wang et al. 2009, Zhou et al. 2009, Zhong et al. 2010). When the WPSH positions itself more southward and westward of its climatological location, the rain band in the northern flank of the WPSH will be more southward than normal, facilitating severe floods in the southern part of the country (Zhang et al. 2007, Wang et al. 2009). This scenario can also be seen in Fig. 2b for the DPE events. The composite wind stream functions and the divergent wind components at $500 \mathrm{hPa}$ (Fig. 2b) show the WPSH is a lot farther westward of its summer climatological position (not shown). An anomalous anticyclonic circulation covers the vast region to the south of southern China, causing the rain belt on the north side of the WPSH to be in the MLRYR, resulting in DPEs occuring there.

A strong anomalous anticyclonic circulation at $200 \mathrm{hPa}$, centered in the southwestern portion of China, is observed in Fig. 2c. This reinforces the Tibetan Plateau high in the southeastern part of China and facilitates the upward motions of air around that region. In mid to higher latitudes north of this anticyclone, an intense cyclonic circulation, which is zonally elongated, is present. The divergent flows emanate from the MLRYR area northward to the cyclonic circulation over northeastern China and southward to the cyclonic circulation over the SCSNWP region. The divergence at $200 \mathrm{hPa}$ over the MLRYR reinforces the low-level cyclone, thereby intensifying the convergence of these flows for the intense precipitation occurrence.

The composite vertical circulations for 93 DPEs show that there are strong updrafts around $30^{\circ} \mathrm{N}$ with 2 circulation centers on both sides of this latitude (Fig. 2d). The strongest upward motion is found around 400 to $500 \mathrm{hPa}$ in the middle troposphere in which the vertical velocity is greater than $8 \mathrm{~Pa} \mathrm{~s}^{-1}$.

The anomalous circulation patterns for DPEs are baroclinic and are displayed in Fig. 2, which shows a significant cyclonic circulation in the MLRYR along with an anticyclonic circulation in the SCS-NWP region in the middle and lower tropospheres, a zonally elongated cyclonic circulation north of the MLRYR and an anticyclonic circulation south of the MLRYR in the upper troposphere. The meridional circulations are well defined along $120^{\circ} \mathrm{E}$ with an ascending branch around $30^{\circ} \mathrm{N}$. Interestingly, occurrences of DPE events seem to be still closely related to circulation anomalies at local and tropical latitudes in the middle and lower troposphere. These aforementioned anomalous circulation features resemble the Type I circulation pattern in general.

\subsection{Water vapor transports}

The summer rainfall departures in the MLRYR region are closely linked to anomalous activities of both the south Asian and the east Asian summer monsoons for the 2 principal water vapor sources (Murakami 1959, Ding 1992). The water vapor in the MLRYR region is transported from the Bay of Bengal, which is associated with the south Asian summer monsoon activity, and also from SCS in relation to the east Asian summer monsoon variations. Strong centers of vapor converge in Jiangsu, Shanghai, Anhui and Jiangxi provinces as well areas out to sea (Fig. 3), suggesting the direct role of water vapor sources in DPE events. The stream functions, derived from the vertically integrated water vapor fluxes, show that the water vapor can indeed be transported horizontally from the Bay of Bengal eastward into the southern part of China. However, for the DPEs, the relatively stronger divergent flows (displayed with arrow 

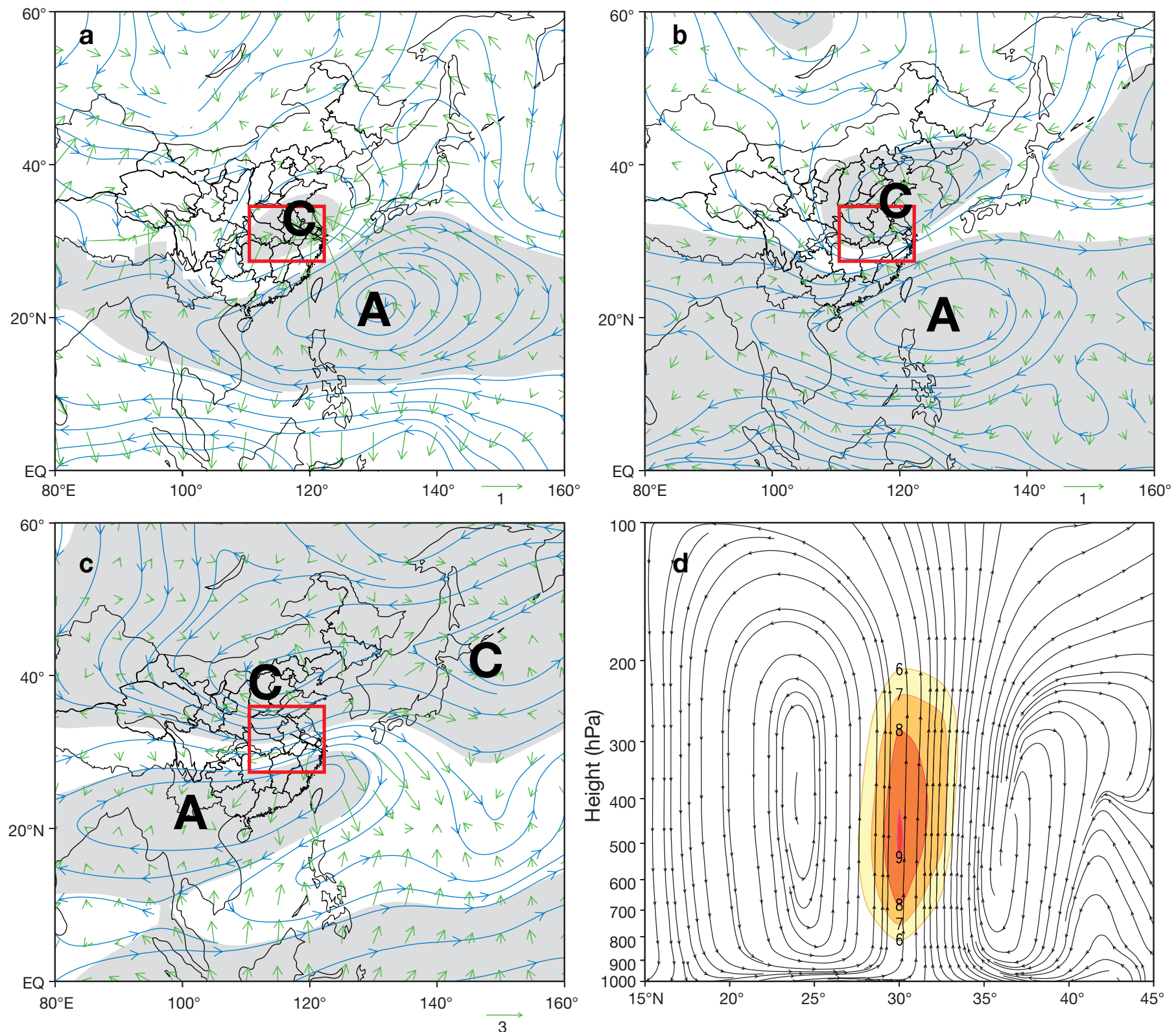

Fig. 2. Mean composite differences of rotational wind (stream lines in blue) and divergent wind components ( $\mathrm{ms}^{-1}$, green vector arrows) for 93 DPE events from the same physical quantities of summer mean climatic conditions for 1979 to 2008. Panels (a), (b) and (c) are for $850 \mathrm{hPa}, 500 \mathrm{hPa}$ and $200 \mathrm{hPa}$, respectively. In panels (a), (b) and (c), the grey shaded areas represent the values above the $95 \%$ confidence level determined with a $t$-test, and the rectangular boxes denote the MLRYR region. Capital letters $\mathrm{A}$ and $\mathrm{C}$ in bold text denote anticyclonic and cyclonic circulations, respectively. Panel (d) is for the latitude-height section of composites of the anomalous vertical circulation averaged over 110 to $125^{\circ} \mathrm{E}$ for the 93 DPEs, where the vertical velocity $\omega$ (in $\mathrm{Pa} \mathrm{s}^{-1}$ ) is enlarged $100 \times$ for arrows, and increasingly larger values of $\omega$ are represented by increased levels of color intensity

vectors in Fig. 3), other than the stream functions, are not only from the region north of the Bay of Bengal and SCS but also from the region north of the convergence zone over the MLRYR. Besides these 2 vapor sources, however, a third vapor source for the DPE events is shown in Fig. 3; the vapor is transported strongly from a location north of the convergence zone in the MLRYR, which plays a very important part in the DPE events. Climate scientists in China seldom pay attention to the water vapor sources over the Asian continent when they discuss the flood events in the MLRYR region. However, this vapor source could be an important factor in the investigation of DPE events. 


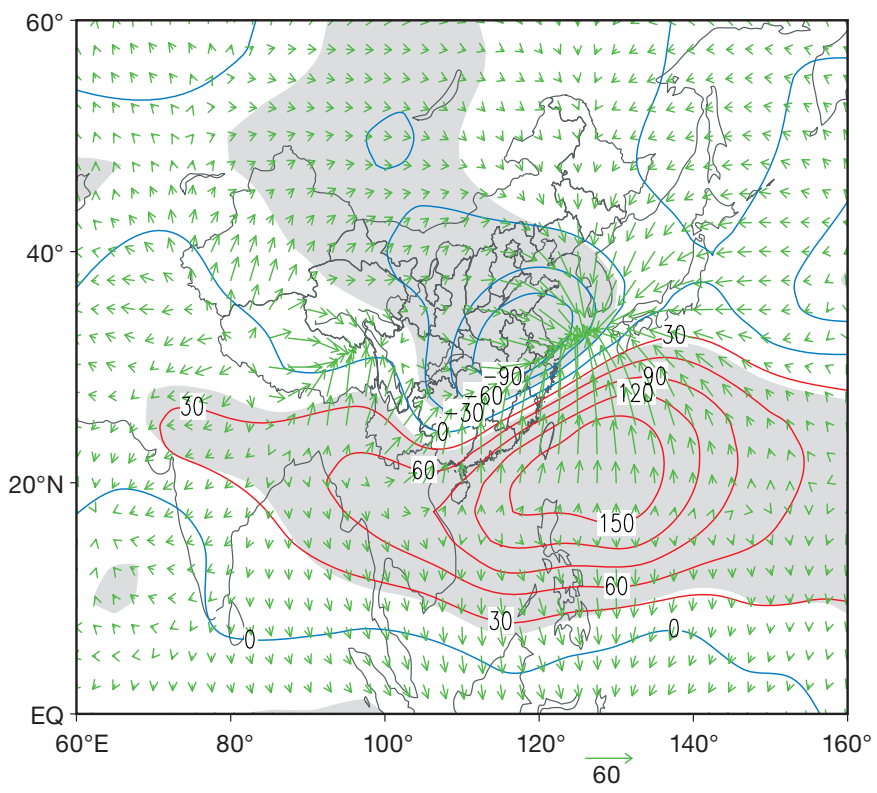

Fig. 3. The mean composites of stream functions $\left(\mathrm{kg} \mathrm{s}^{-1}\right)$ and divergent components $\left(\mathrm{kg} \mathrm{m}^{-1} \mathrm{~s}^{-1}\right)$ for the vertically integrated anomalous vapor fluxes $\left(\mathrm{kg} \mathrm{s}^{-1}\right)$ for the 93 DPEs. Grey shaded areas denote the values above the $95 \%$ confidence level. Contours in red and blue represent positive and negative stream functions, respectively. Vector arrows in green represent the divergent component of the vapor fluxes

\section{EXTERNAL FORCING RELATED TO DPE EVENTS}

\subsection{Heating}

To understand the thermal forcings in DPE events, the atmospheric apparent heat source, $Q_{1}$, and apparent vapor sink, $Q_{2}$, are examined. Referring to Luo \& Yanai (1984), these 2 sources of heating are obtained via the formulae:

and

$$
Q_{1}=c_{p}\left[\frac{\partial T}{\partial t}+V \cdot \nabla T+\left(\frac{p}{p_{0}}\right)^{k} \omega \frac{\partial \theta}{\partial p}\right]
$$

$$
Q_{2}=-L\left(\frac{\partial q}{\partial t}+V \cdot \nabla q+\omega \frac{\partial q}{\partial p}\right)
$$

where the terms on the right-hand sides of the above 2 formulae are of local changes, horizontal advections and vertical transfers. The vertical integration from the surface of the earth up to $300 \mathrm{hPa}$ is conducted for the above expressions, with the integrals denoted within ' $<>$ '. Then:

$$
<Q_{1}>=\frac{1}{g} \int_{p_{\mathrm{s}}}^{p_{T}} Q_{1} \mathrm{~d} p=\left(L P_{\mathrm{r}}+L C-L E\right)+Q_{\mathrm{s}}+<Q_{\mathrm{R}}>
$$

and

$$
<Q_{2}>=\frac{1}{g} \int_{p_{\mathrm{s}}}^{p_{T}} Q_{2} \mathrm{~d} p=\left(L P_{\mathrm{r}}+L C-L E\right)-L E_{\mathrm{s}}
$$

From these equations we obtain

$$
<Q_{1}>-<Q_{2}>=<Q_{\mathrm{R}}>+\left(Q_{\mathrm{s}}+L E_{\mathrm{s}}\right)
$$

In Eqs. (1) through (5), $T$ is temperature, $V$ is horizontal wind velocity, $p$ is pressure. $q$ is specific humidity, $k$ is the ratio of the specific gas constant to the specific heat for a constant pressure, $C_{p}$ is the specific heat for a constant pressure, $L$ is latent heat, $P_{r}$ is the precipitation, $Q_{\mathrm{s}}$ is the sensible heat flux at the earth surface, $E$ is the evaporation of cloud droplets in the air column, $C$ is the condensation rate of water vapor in the air column, $E_{\mathrm{s}}$ is the surface latent heat flux, $\left\langle Q_{\mathrm{R}}\right\rangle$ is the vertically integrated radiative heating (cooling), $p_{\mathrm{s}}$ is the surface pressure and $p_{T}$ $(=300 \mathrm{hPa})$ the top level pressure for integration.

The distribution of departures of both $\left\langle Q_{1}\right\rangle$ and $<Q_{2}>$ averaged over the 93 DPE events from those of the mean summer climatic conditions (Fig. 4a,b) resembles the pattern of stream functions of the column-integrated vapor flux anomalies, showing the large-valued zones in the MLRYR and western Pacific basin (Figs. 3 \& 4). Ding (1992) noted that although the surface sensible heat and evaporation fluxes are small when strong rainfall occurs, the apparent vigorous vapor sinks lead to strong precipitation, which, in turn, causes vast amounts of heat released through condensation into the atmosphere where diabatic heating forcings occur. This diabatic heating can increase the amount of rainfall by intensifying the divergence of the atmosphere in the middle and upper troposphere. Both $<Q_{1}>$ and $\left\langle Q_{2}>\right.$ are of positive anomalies in the MLRYR and the Yellow Sea in relation to the latent heat release from the abundant rainfall (Fig. 4a,b). On the other hand, negative anomalies of $\left\langle Q_{1}\right\rangle$ and $\left\langle Q_{2}>\right.$ are found in the SCS and 'warm pool' area of the western Pacific Ocean, which is probably associated with the anomalous radiative cooling and evaporation in the WSPH domain (L. J. Wang et al. 2008).

The difference between anomalous $\left\langle Q_{1}>\right.$ and anomalous $\left\langle Q_{2}\right\rangle$ represents the anomalous diabatic heating induced by radiation and surface sensible heat flux as seen in Eq. (5). If the difference is small enough, the circulation changes will be driven by only the latent heat release in the dynamic processes. However, if the difference is positive or negative, it means that the transports of radiative heating and surface sensitive/latent heat into the atmosphere are enhanced or reduced, respectively. The difference 

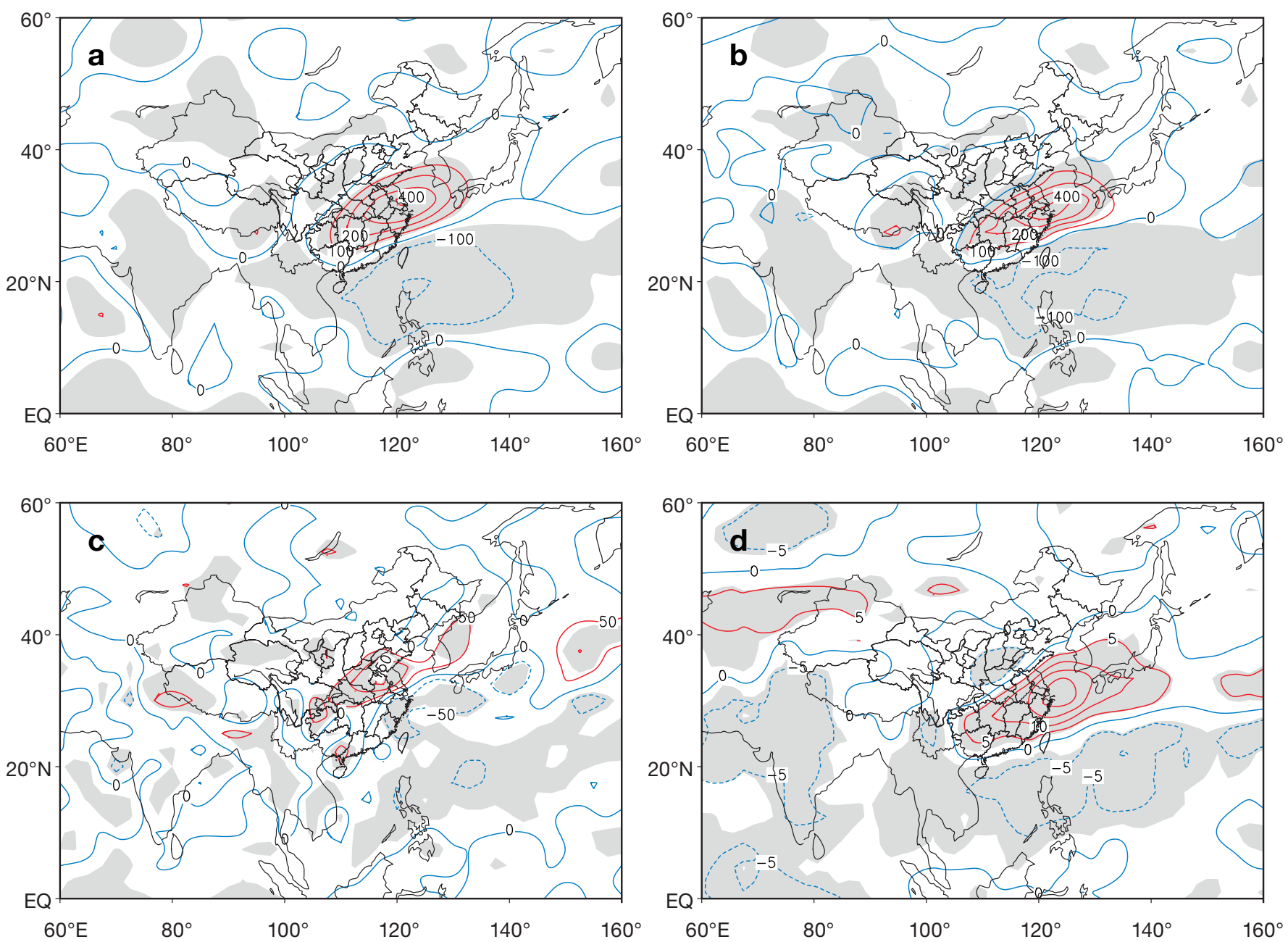

Fig. 4. Mean composite differences (in $\mathrm{W} \mathrm{m}^{-2}$ ) of vertically integrated (a) apparent heat sources $\left\langle Q_{1}>\right.$, (b) apparent vapor sinks $<Q_{2}>$ and (c) $<Q_{1}>-<Q_{2}>$ for 93 DPEs from those of the 1979 to 2008 summer mean climatic conditions. (d) Total cloud amount anomalies in percentages. Grey shaded areas denote values above the $95 \%$ confidence determined with a $t$-test. Positive and negative (incl. zero) values are plotted in red and blue, respectively. Dashed contours: negative values

between the anomalies of $\left\langle Q_{1}>\right.$ and $<Q_{2}>$ is positive in the northern MLRYR (Fig. 4c), suggesting that the energy released into the atmosphere by radiative forcing and surface sensible/latent heat is increased. This positive difference over the region north of the MLRYR is probably due to the smaller cloudiness on the north side of the rain band (Fig. 4d), which is favorable for allowing shortwave radiation to penetrate into the lower troposphere, which will induce more surface sensible heat transport up into the atmosphere and hence, heat the atmosphere, which will lead to the anomalous convergence in the MLRYR region.

The negative difference between anomalies of $\left\langle Q_{1}\right\rangle$ and those of $\left\langle Q_{2}\right\rangle$ is found in the southeasten MLRYR, the Yellow Sea, and the NWP. Over oceans, this is due to the weakened sea surface thermal flux into the air and the amplified radiative cooling that is present for the weakened convective activities (Fig. 4d). Anomalous cooling in the tropics forces the atmosphere to diverge in this region, inducing an anomalous anticyclonic circulation in the lower troposphere northwest of the cooling center (Gill 1980, Ambrizzi \& Hoskins 1997), from which the divergent airflow converges into the MLRYR, which is favorable for the DPE events.

\subsection{SST anomalies}

Sea surface temperature anomalies are the important factor in variations of summer climate conditions in the MLRYR region. In the boreal summer when an El Niño episode has passed its mature stage, the MLRYR rainfall tends to be higher than normal (cf. Guan \& Li 2008). The differences between SSTs aver- 


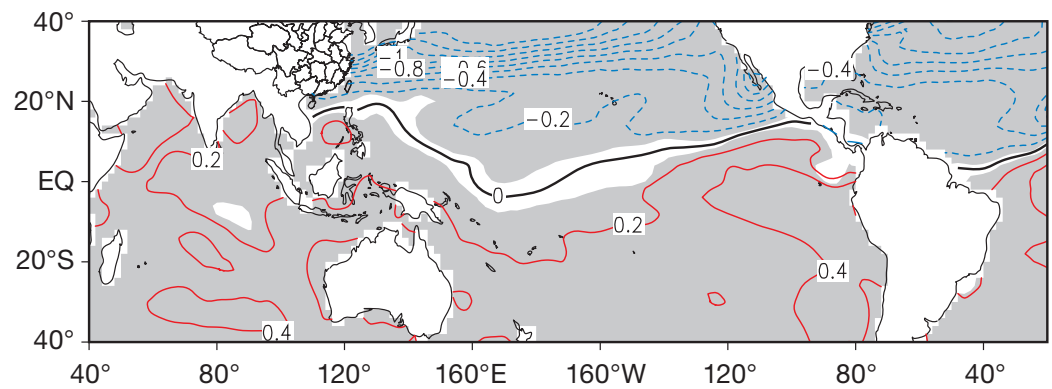

Fig. 5. Mean composites of June, July and August mean SST anomalies $\left({ }^{\circ} \mathrm{C}\right)$ for the 93 DPE events. Grey shaded areas denote the values above the $95 \%$ confidence level determined with a $t$-test. Contours in red and blue are for positive and negative values, respectively

aged over 93 DPE events and those of 1979-2008 mean summer climatic conditions (Fig. 5) show that the positive SSTAs are in the equatorial eastern Pacific and Indian oceans in contrast to the strong negative SSTAs, which are in the North Pacific Ocean. This pattern resembles the distribution of SSTAs in El Niño maturing and damping stages (e.g. Lau \& Nath 2003, Guan \& Li 2008). The SSTs are normally higher in the tropical western Pacific and equatorial Indian oceans, which is known as the 'warm pool'. The anomalously higher SST in the warm pool in the boreal summer is usually in association with higher SSTs of the eastern equatorial Pacific Ocean in the previous winter owing to both the atmospheric bridge and oceanic dynamic processes (cf. Alexander et al. 2002, Zhou et al. 2009). When SSTs are higher than normal in the warm pool and the equatorial Indian Ocean, the western Pacific subtropical high (WPSH) tends to intensify and locate more southwestward compared with its normal position, which facilitates more rainfall events to happen over the MLRYR (cf. Guan \& Li 2008).

\section{THE SECOND TYPE OF DPE-RELATED CIRCULATION PATTERNS}

The DPE-related circulation patterns are obtained by a composite analysis of 93 DPE events. However, we still questioned whether each of the 93 events has a circulation pattern similar to the mean composites of the 93 DPEs. To answer this question, we checked the spatial correlations between the geopotential heights of each of the 93 events with those of the mean composites. Thus, a region from 10 to $50^{\circ} \mathrm{N}$ and from 100 to $140^{\circ} \mathrm{E}$, which covers the MLRYR, is fixed for the spatial correlation study. The 93 spatial correlations of geopotential height anomalies at $500 \mathrm{hPa}$ in the rectangular area, as plotted in Fig. 2 for each DPE event with those averaged over 93 DPE events, are shown in Fig. 6. Among the 93 DPEs, most are highly correlated with the mean composites and have positive correlation coefficients, indicating that the 93 event-mean circulation patterns are the most important, which is the same as shown in Figs. 2 \& 3.

Surprisingly however, 16 of the 93 events are correlated negatively with the mean composites for the 93 events. These negative coefficients in Fig. 6 indicate that the circulations over the MLRYR for these DPE days are very different from those for other DPE days.

\subsection{Circulation features related to the negative correlation events}

The composite analysis of the physical quantities for the 16 negative correlation events (Fig. 6, Table 2) is performed against 77 positive correlation events. For the 77 positive-correlation DPEs, the composite mean circulations (not shown) look very similar to those displayed in Figs. 2 to 5. However, the composite mean circulations for the 16 samples (see Figs. 8 to 10) differ greatly from those for the 93 DPE events (Figs. 2 to 5).

\subsubsection{Precipitation distributions for the negative spatial correlation DPE events}

The spatial distribution of rainfall as well as its anomalies averaged over the 16 DPE events is displayed in Fig. 7 and indicates a similar rainfall pattern in comparison with the composites of $93 \mathrm{DPE}$ (Fig. 1b). Large values (Fig. 7) are found in the zones

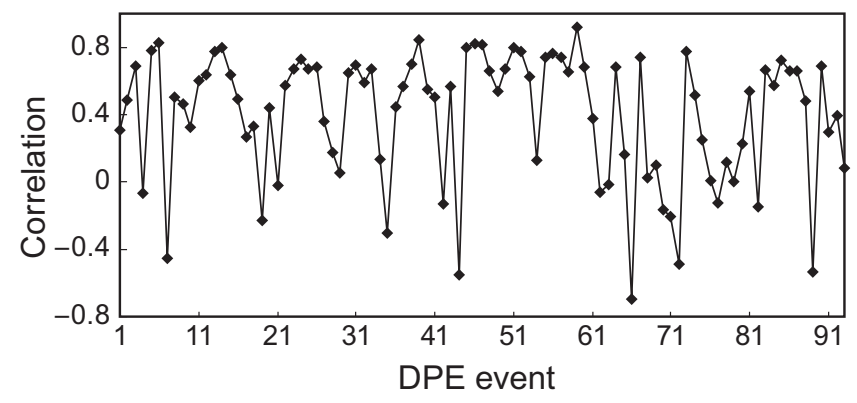

Fig. 6. Spatial correlations of geopotential height anomalies at $500 \mathrm{hPa}$ in the rectangular areas plotted in Fig. 2 for each DPE event with those averaged over 93 DPE events 
Table 2. Dates $(\mathrm{d} / \mathrm{mo} / \mathrm{yr})$ of negative spatial correlations. (T): dates with a typhoon passing through the middle and lower reaches of the Yangtze River

\begin{tabular}{|lclc|}
\hline Date & Rainfall (mm) & \multicolumn{1}{c|}{ Date } & Rainfall $(\mathrm{mm})$ \\
\hline $12 / 8 / 1980$ & 24 & $15 / 7 / 1996$ & 20 \\
$11 / 7 / 1981$ & 21 & $19 / 8 / 1997$ & 29 \\
$31 / 8 / 1984$ & 23 & $22 / 7 / 1998$ & 24 \\
$12 / 6 / 1986$ & 20 & $23 / 7 / 1998$ & 28 \\
$31 / 8 / 1990(\mathrm{~T})$ & 24 & $29 / 7 / 1998$ & 22 \\
$7 / 8 / 1991$ & 25 & $29 / 6 / 1999$ & 23 \\
$31 / 8 / 1992$ & 24 & $7 / 8 / 2002$ & 21 \\
$14 / 7 / 1996$ & 24 & $7 / 8 / 2005(\mathrm{~T})$ & 20 \\
\hline
\end{tabular}

that border the provinces of Anhui, Jiangxi and Zhejiang, where the values are greater than those in the counterpart areas in Fig. 2b,c. There is a weak center with $40 \mathrm{~mm} \mathrm{~d}^{-1}$ in southern Jiangsu province (Fig. 7a), which is not seen in the mean rainfall for the 93 DPEs.

\subsubsection{Circulations and vapor transports of the negative correlation DPEs}

The composite circulation pattern for the 16 negative-correlation DPEs (Fig. 8) differs greatly from that for the 93 DPEs. The composite circulations of the former elongate into meridional instead of into zonal patterns (Figs. $2 \& 8$ ). At lower levels in the troposphere (Fig. 8a) the MLRYR is under the control of an anomalous cyclone, with a strong anomalous anticyclone to the northeast and a tropical anticyclone over the SCS. Evidently, the anomalous cyclone over the MLRYR looks deep enough, tilting a little westward from the lower to upper troposphere (Fig. 8a-c).
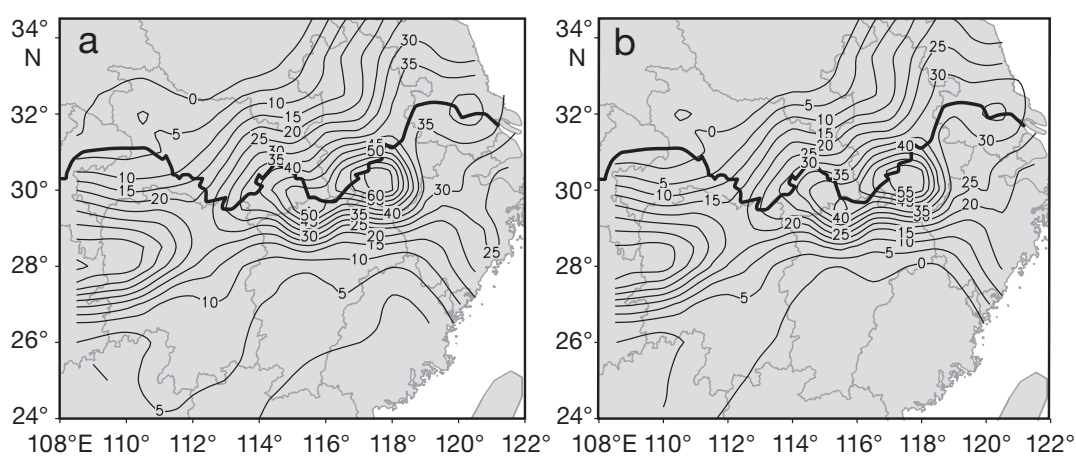

Fig. 7. (a) Mean rainfall $\left(\mathrm{mmd}^{-1}\right)$ over the 16 DPE events (see Section 6 ), and (b) departures of the mean rainfall $\left(\mathrm{mm} \mathrm{d}^{-1}\right)$ of the 16 events from seasonal mean rainfall for 1979 to 2008 summer climatic conditions. The thick solid line represents the Yangtze River
Uccellini \& Johnson (1979) investigated the coupling of upper and lower tropospheric jet streaks, indicating the importance of this interaction between lower and upper troposphere in the development of organized severe convective storm systems. The deep circulation system displayed in Fig. 8 suggests that there is some interaction between the upper and lower troposphere, which is possibly induced by the strong vertical exchanges of horizontal momentum. To clarify this, further investigations with numerical experiments and data analyses are needed for a particular case or for all 16 cases.

The anomalous vertical circulations are also well defined (Fig. 8d) compared with those in Fig. 2d, but the positions of the vertical cells and the maximum of vertical velocity shift northward by approximately $5^{\circ}$. The water vapor is transported from the SCS and the tropical western Pacific Ocean, as evident from the stream function field in Fig. 8e. However, the fact remains that the water vapor converges into the MLRYR from not only the SCS and the tropical western Pacific, but also from the extratropical region east of the MLRYR, which is greatly different from the scenario of composites for the 93 DPE events.

The circulations favorable for the 16 DPEs are significant above the $95 \%$ level of confidence in the MLRYR area and in mid to high latitudes other than in the tropics except the eastern Indian Ocean (Fig. 7), which is very different from those for the 93 DPEs (Fig. 2). This suggests that the disturbances in mid to high latitudes are more important in these 16 daily precipitation extremes than in the other DPEs.

There are 2 cases in Table 2 in which typhoons passed through the MLRYR region. If these 2 typhoon cases are removed, the composites for 14 out of the 16 negative-correlation DPE events look very similar to those of the composites for the 16 negative-correlation DPEs (not shown), suggesting that the influences of typhoons on the aforementioned results can be ignored.

\subsection{Diabatic heating and SST anomalies for negative correlation events}

\subsubsection{Anomalous diabatic heating}

For the 16 events of the negativecorrelation DPEs, the vertically integrated apparent heat sources and va- 

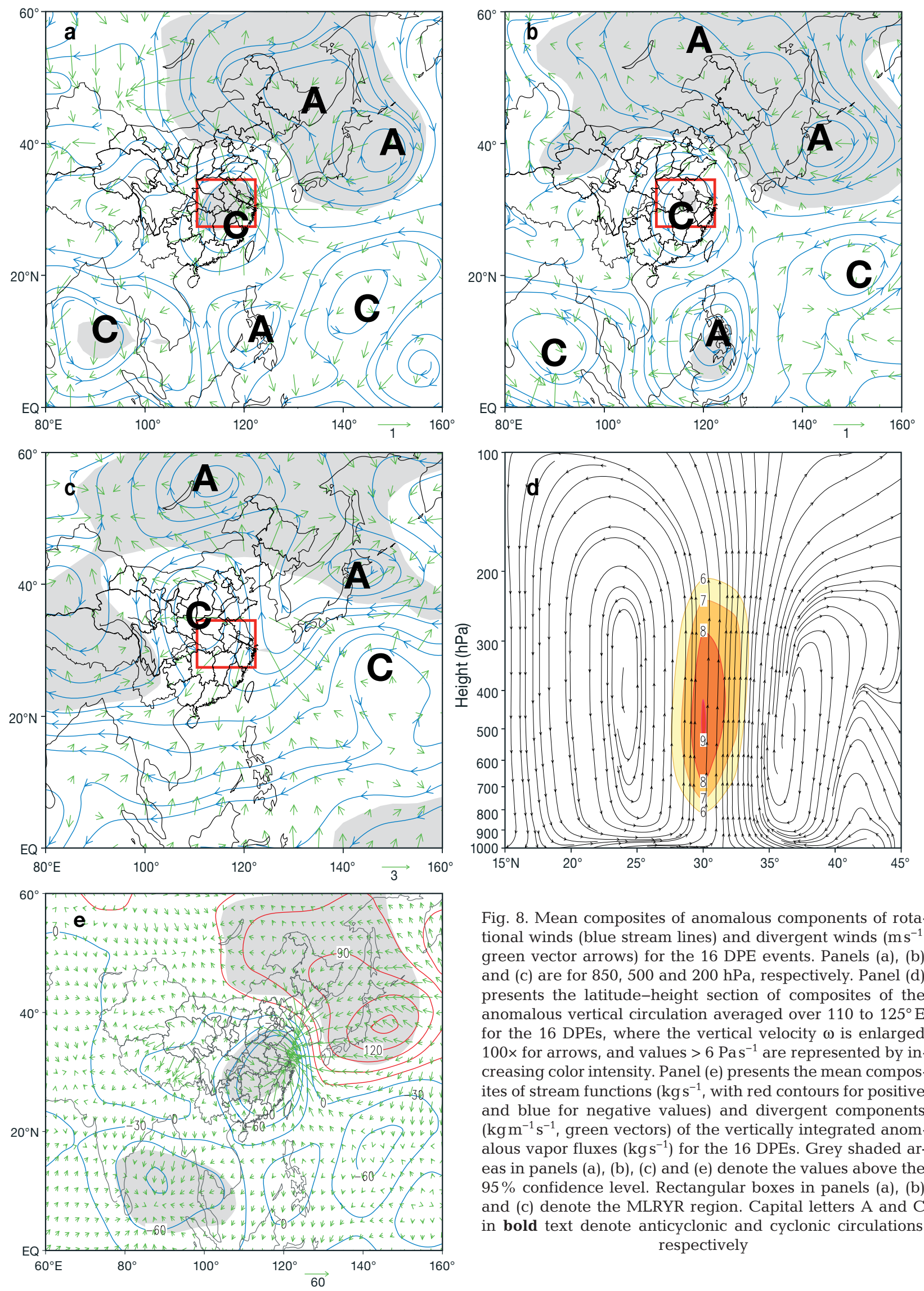

Fig. 8. Mean composites of anomalous components of rotational winds (blue stream lines) and divergent winds $\left(\mathrm{ms}^{-1}\right.$, green vector arrows) for the 16 DPE events. Panels (a), (b) and (c) are for 850, 500 and $200 \mathrm{hPa}$, respectively. Panel (d) presents the latitude-height section of composites of the anomalous vertical circulation averaged over 110 to $125^{\circ} \mathrm{E}$ for the 16 DPEs, where the vertical velocity $\omega$ is enlarged $100 \times$ for arrows, and values $>6 \mathrm{~Pa} \mathrm{~s}^{-1}$ are represented by increasing color intensity. Panel (e) presents the mean composites of stream functions $\left(\mathrm{kg} \mathrm{s}^{-1}\right.$, with red contours for positive and blue for negative values) and divergent components $\left(\mathrm{kg} \mathrm{m}^{-1} \mathrm{~s}^{-1}\right.$, green vectors) of the vertically integrated anomalous vapor fluxes $\left(\mathrm{kg} \mathrm{s}^{-1}\right)$ for the 16 DPEs. Grey shaded areas in panels (a), (b), (c) and (e) denote the values above the $95 \%$ confidence level. Rectangular boxes in panels (a), (b) and (c) denote the MLRYR region. Capital letters A and C in bold text denote anticyclonic and cyclonic circulations, respectively 

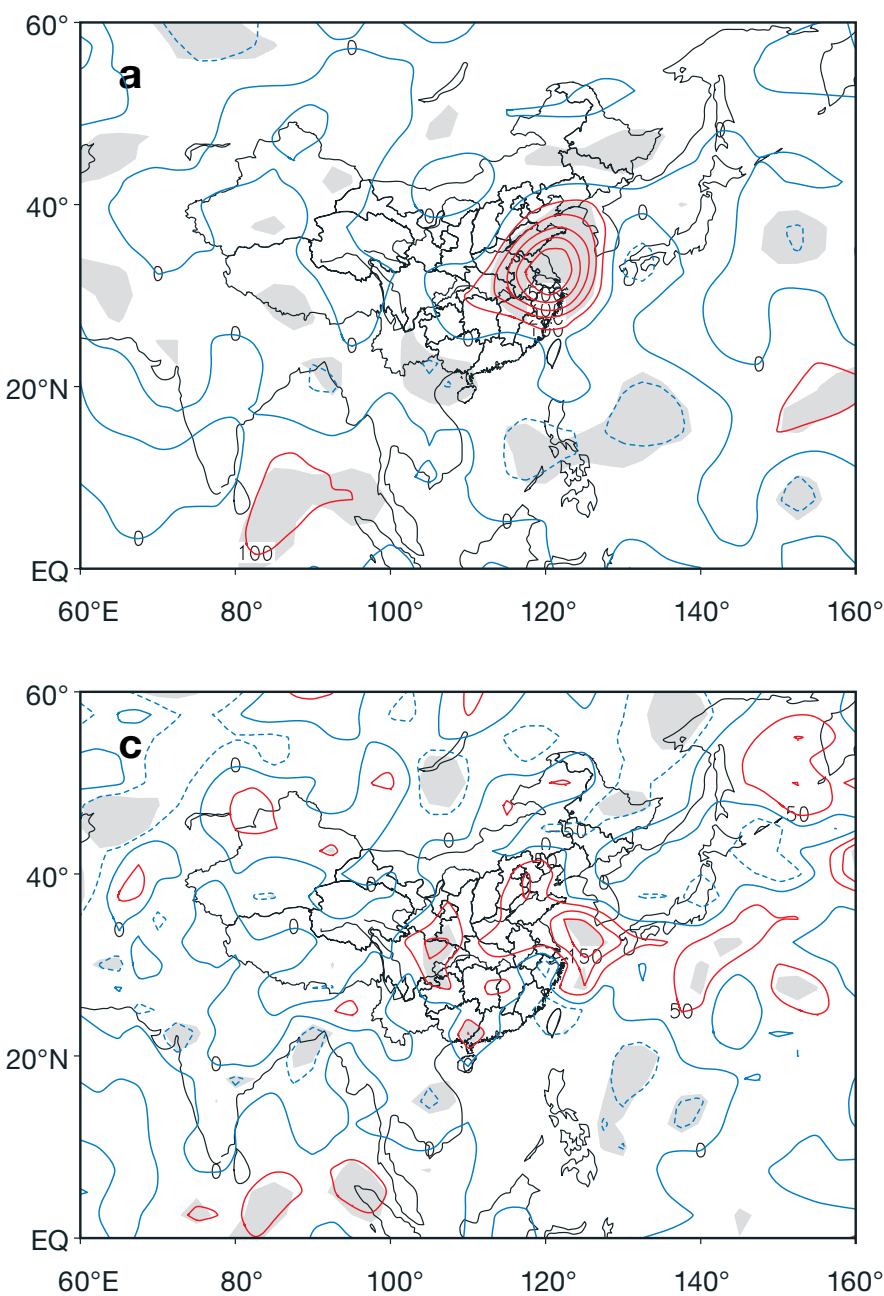

por sinks presented in Fig. 9 show the maximum positive-value centers in the eastern MLRYR. Their size is considerably smaller than that of the diabatic heating composites for the 93 DPEs and is associated with latent heat release due to precipitation. A relatively strong negative departure center east of the Philippines for the differences between anomalies of $\left\langle Q_{1}\right\rangle$ and of $\left\langle Q_{2}>\right.$ in Fig. 9c, indicative of anomalous cooling, is smaller compared with that in Fig. 4, which is in association with the SCS anticyclonic circulation. This anticyclonic circulation is favorable for the divergence of water vapor in the lower troposphere into the MLRYR and induces DPEs to occur there.

\subsubsection{SST anomalies}

The composite SSTA for the 16 DPEs show an opposite pattern in comparison with that for the 93 DPE events. In Fig. 10, the positive, large, SSTAs are

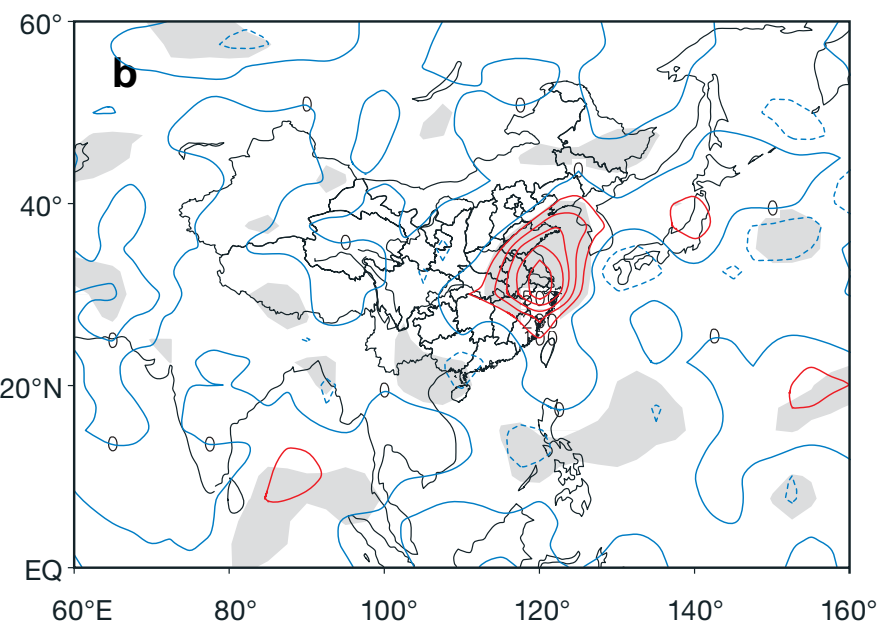

Fig. 9. Mean composites (in $\mathrm{Wm}^{-2}$ ) of anomalous vertically integrated (a) apparent heat sources $\left\langle Q_{1}\right\rangle$, (b) apparent vapor sink $<Q_{2}>$ and (c) $<Q_{1}>-<Q_{2}>$ for the 16 DPEs. Grey shaded areas denote values above the $95 \%$ confidence level determined with a $t$-test. Positive and negative values are plotted in red and blue, respectively

found in the extratropics of both the north Pacific and Atlantic oceans in the boreal summer. However, significant SSTAs are only found in the western Indian Ocean although a La Niña-like pattern exists in the tropics. These results suggest that there are 2 types of SSTA patterns that possibly influence the 2 types of anomalous circulation patterns under which the DPEs may occur. However, how the SSTAs affect the DPE via circulation changes is still not clearly understood. This needs to be clarified by numerical simulations.

\section{SUMMARY}

The composite analysis of anomalous circulations and thermal forcings was performed for the daily precipitation extreme events in the middle and lower reaches of the Yangtze River of China during the boreal summer over the past $30 \mathrm{yr}$. The results are summarized as follows.

The threshold value of regionally averaged daily rainfall in summers from 1979 to 2008 was $19 \mathrm{mmd}^{-1}$ in terms of the definition of daily precipitation extremes. There have been 93 DPE events in the past $30 \mathrm{yr}$ in the MLRYR. These DPE events occurred with different frequencies from one decade to another. In the 1990s, more DPE events occurred in the MLRYR region than in any other decade. 


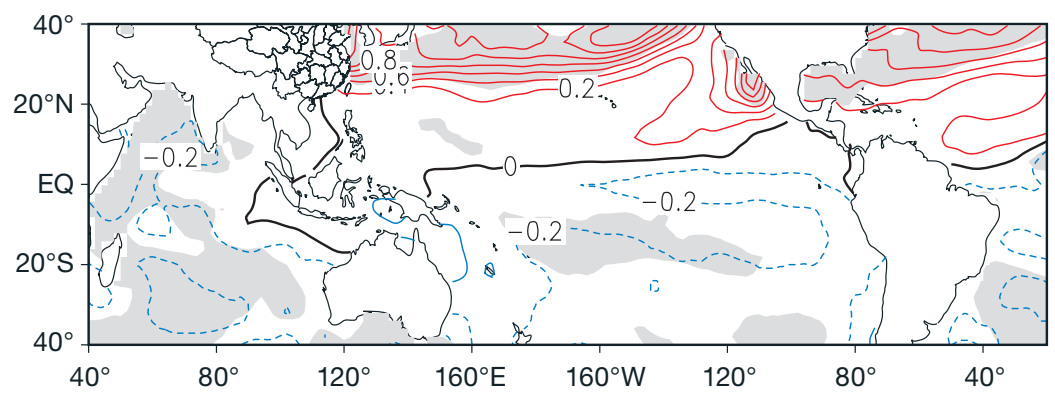

Fig. 10. Mean composite of June, July and August mean SST anomalies $\left({ }^{\circ} \mathrm{C}\right)$ for the 16 DPE events. Grey shaded areas denote the values above the $95 \%$ confidence level determined with a $t$-test. Contours in red and blue represent positive and negative values, respectively

Most of the 93 events shared similar circulation features in the MLRYR region in the middle troposphere. However, there were 16 cases whose circulation features differed greatly from those of the rest of 93 events. Hence, 2 types of anomalous circulation patterns along with the water vapor transports and thermal forcings that facilitate the DPEs have been found. These 2 patterns of circulation anomalies along with distributions of other physical quantities differed greatly from each other.

A Type I circulation pattern is characterized by an anomalous cyclone over the MLRYR and an anomalous anticyclone in the SCS and tropical NWP in the lower and middle troposphere. In the upper troposphere, an anomalous anticyclone is located in the region south of the MLRYR, and an anomalous cyclonic circulation is present in the region north of the MLRYR. All these anomalous circulations elongate in a zonal direction. The vertical meridional circulations are well defined around $120^{\circ} \mathrm{E}$ with upward motion over the MLRYR. The water vapor converges into the MLRYR from the Bay of Bengal, SCS, NWP and areas northwest of the MLRYR. Such anomalous circulation conditions are favorable for the intensified convections and, hence, induce the DPE events to occur. Besides, it seems that occurrences of the DPEs are more significantly related to circulation anomalies in mid to lower latitudes than in higher latitudes.

In association with a Type I circulation pattern, the apparent heat sources, vapor sinks and the SSTAs are responsible for inducing the circulation changes. The strong heating, which is mainly induced by latent heat release, is found in the MLRYR region while cooling occurs in the tropical northwestern Pacific. This thermal-forcing contrast is favorable for intensifying the anomalous vertical meridional circulations in eastern Asia. The strong net apparent heating is observed in regions south of the MLRYR and the tropical NWP and forces the atmosphere to pro- duce an anomalous anticyclone in the SCS and tropical NWP, which facilitates the divergent airflow to emanate from these regions into the MLRYR area. The SSTA features in the IndoPacific sector in association with the Type I circulation pattern look similar to the features of El Niño in its maturing and decaying phases. This SSTA pattern in summertime is well known to be favorable for the flood occurrences in the MLRYR in China.

A Type II circulation pattern for the 16 DPE events is characterized by a very deep anomalous cyclone that tilts westward from the lower to the upper troposphere, and an anomalous anticyclonic circulation at low to mid levels over the SCS and regions northeast of the MLRYR. The anomalous circulations tend to elongate in a more meridional way or be round in shape. The airflow along with water vapor converges into the MLRYR from not only the SCS and tropical NWP but also the ocean area east of China coastlines.

For the Type II circulation pattern, vertically integrated apparent heat sources and vapor sinks show that the maximum positive value also centers in the eastern MLRYR. Over the waters to the east of the Philippines there is a distinct anomalous cooling center that favors air divergence at lower levels of the troposphere. It is surprising that, for the $16 \mathrm{DPE}$ events, the large positive SST anomalies are observed in extratropical oceans in the Northern Hemisphere, which is opposite to the scenarios of SSTAs related to the Type I circulation pattern.

It is worth noting that SSTAs are persistent, thereby providing DPEs a large-scale background. In the background of both SSTA patterns in association with Type I and Type II circulation patterns, daily precipitation extremes may occur.

The results mentioned above have demonstrated 2 types of scenarios in association with the circulation anomalies and thermal-forcing patterns for the regional DPE events in the MLRYR. These scenarios are helpful in understanding why and how the regional DPEs probably occur during summertime. The anomalous cooling in the SCS and the tropical NWP, the water vapor source over land and oceans and the cyclonic/anticyclonic circulation systems are crucial in inducing DPE events. However, why and how the 2 types of anomalous circulation patterns are formed remains unclear.

The persistent SSTAs in tropical Indo-Pacific oceans along with those in the mid-latitude portion of the 
Pacific Ocean play an important role in the occurrences of DPE events. Only 16 cases out of 93 examined are in association with the colder equatorialwarmer extratropical SSTA pattern (Fig. 10), implying that DPEs in the MLRYR may occur more frequently in the presence of the warmer tropical-colder extratropical SST anomalies (Fig. 5). Although a considerable amount of literature in climate research has reported the related results on the influences of ENSO on the flood and drought events in the MLRYR (cf. Guan \& Li 2008), the mechanisms underlying how the aforementioned SSTA patterns affect the rainfall extremes in the MLRYR are still unclear and need to be investigated in the future.

Acknowledgements. The authors thank 2 anonymous reviewers for their helpful comments. The authors also thank the Nanjing Atmospheric Data Center at Nanjing University of Information Science and Technology for the data services. NCEP/NCAR reanalysis are from the website at www.esrl. noaa.gov/psd/data/gridded/. Most of the figures in this paper were prepared with GrADS software. This work is jointly supported by the National Key Technology R\&D Program (Grant No. 2007BAC29B02) and PAPD project of Jiangsu.

\section{LITERATURE CITED}

Alexander MA, Blade I, Newman M, Lazante JR, Lau NC, Scott JD (2002) The atmospheric bridge: the influence of ENSO teleconnections on air-sea interaction over the global oceans. J Clim 15:2205-2231

Ambrizzi T, Hoskins BJ (1997) Stationary Rossby-wave propagation in a baroclinic atmosphere. Q J R Meteorol Soc 123:919-928

Bi BG, Zhang GC, Li ZC (2004) The relationship of abnormal features of the western Pacific subtropical high with the 2003 Huaihe River flood, with the causes explored. J Trop Meteorol 20:505-514 (in Chinese)

Buffoni L, Manger M, Nanni T (1999) Precipitation in Italy from 1833 to 1996. Theor Appl Climatol 63:33-40

Cavazos T (1999) Large-scale circulation anomalies conducive to extreme precipitation events and derivation of daily rainfall in northeastern Mexico and southeastern Texas. J Clim 12:1506-1523

CMA (China Meteorological Administration) National Climate Center (1999) 1998 severe flood and climate anomaly over China. China Meteorological Press, Beijing (in Chinese)

Ding Y (1992) Summer monsoon rainfall in China. J Meteorol Soc Jpn 70:373-396

Ding Y (1993) Research into the persistent extreme rainstorm event over the Jiang-Huai Basin in 1991. China Meteorological Press, Beijing

Gill AE (1980) Some simple solutions for heat-induced tropical circulation. Q J R Meteorol Soc 106:447-462

Gong DY, Wang SW, Zhu JH (2000) Surplus summer rainfall along the middle to lower reaches of the Changjiang River in the 1990s. Acta Geogr Sin 55:567-575 (in Chinese)
Groisman PY, Karl TR, Easterling DR, Knight RW and others (1999) Changes in the probability of heavy precipitation: important indicators of climate change. Clim Change 42: 243-283

Guan ZY, Li LP (2008) Interannual variability of summer climate of China in association with ENSO and the Indian Ocean dipole. In: Fu CB, Jiang ZH, Guan ZY, He JH, Xu ZF (eds) Regional climate studies of China. Springer, Berlin, p 120-147

> Jones C (2000) Occurrence of extreme precipitation events in California and its relationship with the MaddenJulian Oscillation. J Clim 13:3576-3587

Jones PD, Raper SCB, Bradley RS (1986) Northern Hemisphere surface air temperature variation: 1851-1984. J Clim Appl Meteorol 25:161-179

Kalnay E, Kanamitsu M, Kistler R, Collons W and others (1996) The NCEP/NCAR 40-year reanalysis project. Bull Am Meteorol Soc 77:437-471

Kunkel KE, Andsager K, Easterling DR (1999) Long-term trends in extreme precipitation events over the conterminous United States and Canada. J Clim 12:2515-2527

> Lau NC, Nath MJ (2003) Atmosphere-ocean variations in the Indo-Pacific sector during ENSO episodes. J Clim 16: $3-20$

> Li XD, Zhu YF, Qian WH (2002) Spatiotemporal variations of summer rainfall over eastern China during 1880-1999. Adv Atmos Sci 19:1055-1068

Li F, Ding YH, Bao YY (2008) A study of the forming characteristics of blocking high in northern Asia during the flood period of the Huaihe River Basin in 2003. J Atmos Sci 32:469-480 (in Chinese)

Liu XN (1999) Climatic characteristics of extreme rainstorm events in China. J Catastrophol 14:55-59 (in Chinese)

Luo HB, Yanai M (1984) The large-scale circulation and heat sources over the Tibetan Plateau and surrounding areas during the early summer of 1979. Part II: heat and moisture budgets. Mon Weather Rev 112:966-989

> Manton MJ, Della-Marta PM, Haylock MR, Hennessy KJ and others (2001) Trends in extreme daily rainfall and temperature in Southeast Asia and the South Pacific: 1961-1998. Int J Climatol 21:269-284

Murakami T (1959) The general circulation and water vapor balance over the Far East during the rainy season. Geophys Mag 29:131-171

Nitta T (1987) Convective activities in the tropical Western Pacific and their impact on the Northern Hemisphere summer circulation. J Meteorol Soc Jpn 65:373-390

> Osborn TJ, Hulme M, Jones PD, Basnett TA (2000) Observed trends in the daily intensity of United Kingdom precipitation. Int J Climatol 20:347-364

Qian WH, Liu X (2005) Regional trends in recent precipitation indices in China. Meteorol Atmos Phys 90:193-207

> Rakhecha PR, Soman MK (1994) Trends in the annual extreme rainfall events of 1-3 day duration over India. Theor Appl Climatol 48:227-237

Stone DA, Weaver AJ, Zwiers FW (1999) Trends in Canadian precipitation intensity. Atmos Ocean 2:321-347

Su BD, Jiang T, Ren GY, Chen ZH (2006) Observed trends of precipitation extremes in the Yangtze River basin during 1960 to 2004. Adv Clim Change Res 2:9-14 (in Chinese)

- Uccellini LW, Johnson DR (1979) The coupling of upper and lower tropospheric jet streaks and implications for the development of severe convective storms. Mon Weather Rev 107:682-703

Wang J, Jiang ZH, Yan ML, Zhang JL (2008) Trends of 
extreme precipitation indices in the mid-lower Yangtze River Valley of China during 1960-2005. Sci Meteorol Sin 28:384-388 (in Chinese)

Wang LJ, Guan ZY, He JH (2008) The circulation background of extremely heavy rain causing severe floods in the Huaihe river valley in 2003 and its relationships to apparent heating. Sci Meteorol Sin 28:1-7 (in Chinese)

Wang LJ, Chen X, Guan ZY, He JH (2009) Features of shortterm position variation of the western Pacific subtropical high during the torrential rain causing severe floods in Southern China and its possible cause. Chin J Atmos Sci 9:1047-1057 (in Chinese)

Xie ZQ, Jiang AJ, Du Y, Ding YH (2005) Spatiotemporal features of annual extremes of heavy precipitation processes in the Yangtze River delta. J Nanjing Inst Meteorol 28: 267-274 (in Chinese)

Yamamoto R, Sakurai Y (1999) Long-term intensification of extremely heavy rainfall intensity in the recent 100 years. World Resour Rev 11:271-281

Zhai PM, Pan XH (2003) Change in extreme temperature and precipitation over Northern China during the second half of the 20th century. Acta Geogr Sin 58(Suppl):1-10 (in Chinese)

Zhai PM, Zou XK (2005) Changes in temperature and precipitation and their impacts on drought in China during 1051-2003. Adv Clim Change Res 1:16-18 (in Chinese)

Submitted: February 28, 2011; Accepted: August 29, 2011
Zhai PM, Zhang X, Wan H, Pan X (2005) Trends in total precipitation and frequency of daily precipitation extremes over China. J Clim 18:1096-1108

Zhang M, Zhang DL, Wang AS (2009) Numerical simulation of torrential rainfall and vortical hot towers in a midlatitude mesoscale convective system. Atmos Ocean Sci Lett 2:189-193

Zhang TY, Sun ZB, Ni DH, Yang S (2007) Regional characteristics of summer precipitation over the mid-lower reaches of the Yangtze during the last 45 years. J Nanjing Inst Meteorol 4:530-537 (in Chinese)

Zhang YL, Cheng BY, Ding YG (2003) Statistical features of rainfall extremes in the Huang-Huai area. J Nanjing Inst Meteorolol 20:71-75 (in Chinese)

Zhang YL, Gao QZ, Ding YG, Jiang T (2006) Analysis of spatiotemporal characteristics and evolutional trends of summer precipitation in the Yangtze River catchment. J Trop Meteorol 22:162-168 (in Chinese)

Zhao P, Zhang R, Liu J, Zhou X, He J (2007) Onset of southwesterly wind over eastern China and associated atmospheric circulation and rainfall. Clim Dyn 28:797-811

Zhong Z, Wang X, Min J (2010) Testing the influence of western Pacific subtropical high... Theor Appl Climatol 100:67-78

Zhou T, Yu R, Zhang J, Drange H and others (2009) Why the Western Pacific Subtropical High has extended westward since the late 1970s. J Clim 22:2199-2215

Proofs received from author(s): November 11, 2011 